\section{UM DESTILADOR DE MERCÚRIO}

Recentemente tivémos que destilar cerca de $18 \mathrm{~kg}$ de mercúrio para encher o reservatório de um manómetro.

Após duas tentativas frustradas de realizar esta destilação, a primeira utilizando como refrigerante o próprio ar e a segunda recorrendo a um refrigerador de Liebig, tentámos o dispositivo de refrigeração esquematizado na figura 1, que representa em linhas gerais o sistema de destilação utilizado.

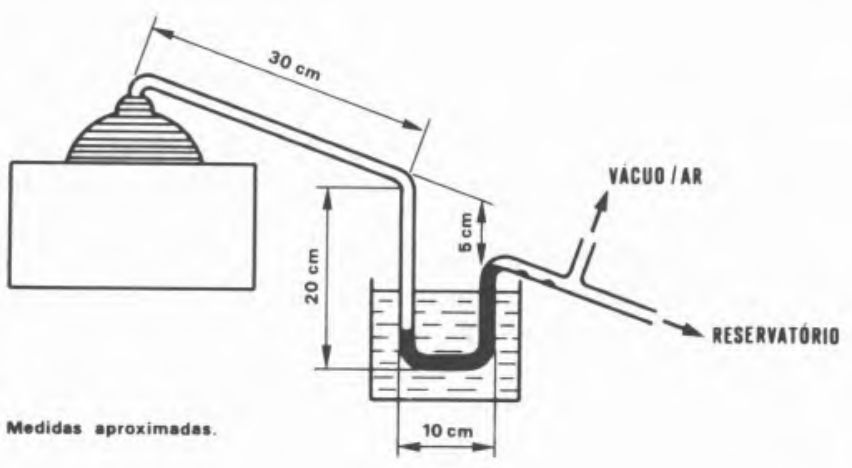

O mercúrio previamente lavado (com ácido azótico a $10 \%$, água destilada e por fim acetona) foi introduzido num balão colocado numa manta de aquecimento, envolvido em papel de amianto (para manter todo o balão igualmente aquecido e evitar assim a condensação dos vapores de mercúrio no próprio balão). Deste recipiente sai um tubo de vidro (diâmetro interno $\pm 7.5 \mathrm{~mm}$ ) que forma um U e continua descendo, a um nível já inferior, para o reservatório. $\mathrm{O} U$ de vidro mergulha numa tina com água $( \pm 2.51)$. Antes do reservatório de mercúrio existe uma saída para ligação ao vácuo/ar.

Com este aparelho destilámos os cerca de $18 \mathrm{~kg}$ de mercúrio em cinco dias e meio de trabalho. As vantagens
Carlos A. R. Nuno

Susana F. Barreiros

Manuel Nunes da Ponte

Centro de Química Estrutural, Complexo 1

I.S.T., Lisboa que ele apresenta relativamente a outros tipos de destiladores para o mesmo fim são muitas:

- baixo custo.

- facilidade de execução: pode ser feito por uma pessoa possuindo poucos conhecimentos de sopragem de vidro.

- eficiência: como se pode verificar pelos valores indicados acima.

- segurança: não há vapores de mercúrio libertados para a atmosfera de trabalho.

- possibilidade de se fazer vácuo no decurso da destilação: no nosso caso concreto surgiu-nos uma pequena fuga de ar para dentro da instalação ao nível do reservatório. Uma vez que ao sair do U de vidro o mercúrio está à temperatura ambiente e a sua pressão de vapor é praticamente nula, pudemos manter o vácuo no sistema durante a destilação.

- por regulação conveniente do aquecimento da manta consegue-se que a zona de condensação do mercúrio não se estenda demasiado até à linha de água. Assim, o vidro acima desta linha conserva-se apenas morno e ou nem é necessário mudar a água ou basta fazê-lo uma vez durante o dia de trabalho.

- para destilar uma nova carga de mercúrio corta-se o tubo de vidro antes do $\mathrm{U}$, endireita-se, enche-se de novo o balão e refaz-se o esquema de montagem.

- pode destilar-se mercúrio "em série": o tubo de vidro a seguir ao $U$ pode acabar num esmerilado (como não há vapores de mercúrio aquecido nessa zona, uma rodagem não constitui problema; usar-se-ia fita de teflon, por exemplo, em vez de 'grease"). Este esmerilado pode estar ligado a dois vasos de recolha por meio de um adaptador bifurcado com duas torneiras de teflon seguidas de esmerilado, com hipótese de ligação ao vácuo. Uma vez cheio o primeiro vaso, abre-se a segunda torneira e, enquanto o segundo vaso enche, o primeiro é substituído por outro, etc.

\section{TERMINOLOGIA, SÍMBOLOS E CONVENÇÕES}

Na continuação da coluna iniciada no n.$^{\circ}$ anterior, incluem-se neste número convençð̃es relativas a gráficos e tabelas.

\section{Convenções para gráficos e tabelas}

O símbolo para uma grandeza representa o produto de um valor por unidade. Assim, por exemplo, V de volume em $V=5 \mathrm{~cm}^{3}$ significa $V=5 \times 1 \mathrm{~cm}^{3}$ pelo que
Mariana P. B. A. Pereira

Maria Estela Jardim

Faculdade de Ciências de Lisboa

$5=\frac{V}{\mathrm{~cm}^{3}}$ ou $5=\underline{V} / \mathrm{cm}^{3}$.

Num gráfico, usa-se o eixo vertical para a variável dependente em função da variável independente, no eixo horizontal. Nos eixos escrevem-se números pelo que se deve indicar no gráfico a grandeza física a dividir pela unidade; aplica-se a mesma regra para as tabelas. $\mathrm{O}$ uso do traço para indicar divisão da grandeza física pela sua 
vontade tem vantagens desde que não se use o traço de divisão para a unidade derivada; por exemplo, a unidade de concentração deve ser escrita mol $\mathrm{dm}^{-3}$ em vez de $\mathrm{mol} / \mathrm{dm}^{3}$.

Assim, para uma titulação em que se adiciona hidróxido de sódio (concentração $=0,100 \mathrm{~mol} \mathrm{dm}^{-3}$ ) a $1,00 \times$ $\times 10^{2} \mathrm{~cm}^{3}$ de ácido clorídrico $\left(\mathrm{c}=0,100 \mathrm{~mol} \mathrm{dm}^{-3}\right)$ tem-se o seguinte quadro de valores e gráfico:

\begin{tabular}{c|c|c}
\hline $\begin{array}{c}\text { volume adicionado/ } \\
\mathrm{cm}^{3}\end{array}$ & $\begin{array}{c}{\left[\mathrm{H}^{+}\right] /} \\
\mathrm{mol} \mathrm{dm}^{-3}\end{array}$ & $p H$ \\
\hline 0,0 & $1,00 \times 10^{-3}$ & 1,00 \\
10,0 & $2,2 \times 10^{-2}$ & 1,08 \\
50,0 & $5,0 \times 10^{-2}$ & 1,47 \\
90,0 & $5,3 \times 10^{-3}$ & 2,28 \\
100,0 & $1,00 \times 10^{-7}$ & 7,0 \\
110,0 & $2,10 \times 10^{-12}$ & 11,7 \\
120,0 & $1,10 \times 10^{-13}$ & 13,0 \\
\hline
\end{tabular}

Quando em gráficos ou tabelas figuram númeos que podem ser escritos sob notação científica, incluiu-se a potência de 10 juntamente com a unidade. Assim, para a

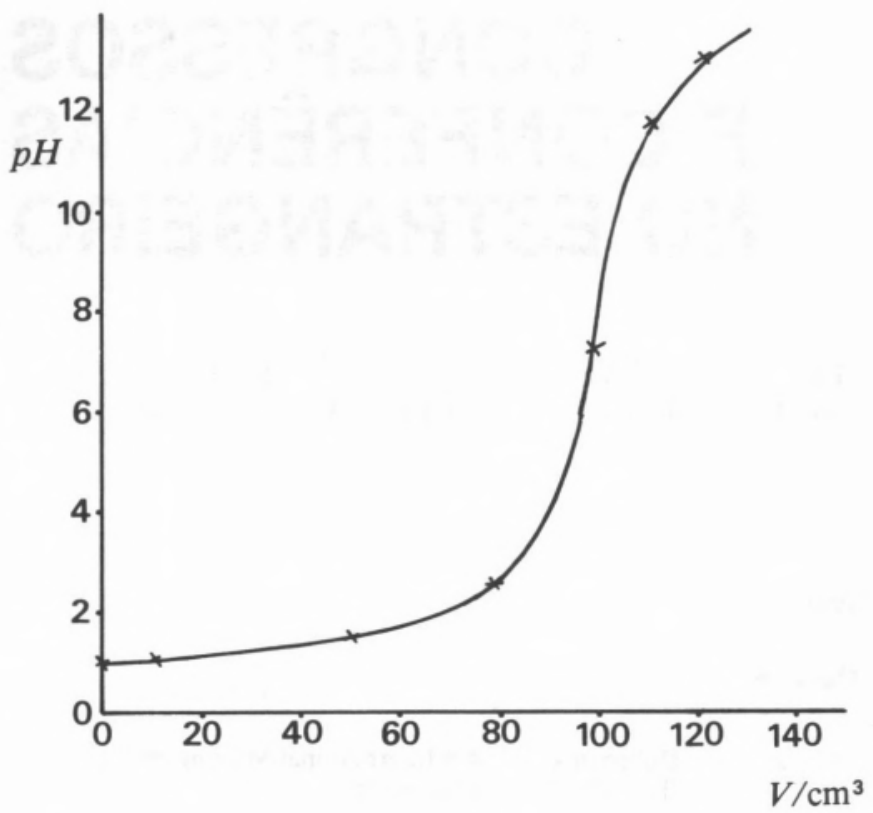

representação da energia de $1 .{ }^{\mathrm{a}}$ ionização em função do n. ${ }^{\circ}$ atómico, pode usar-se qualquer dos seguintes gráficos:

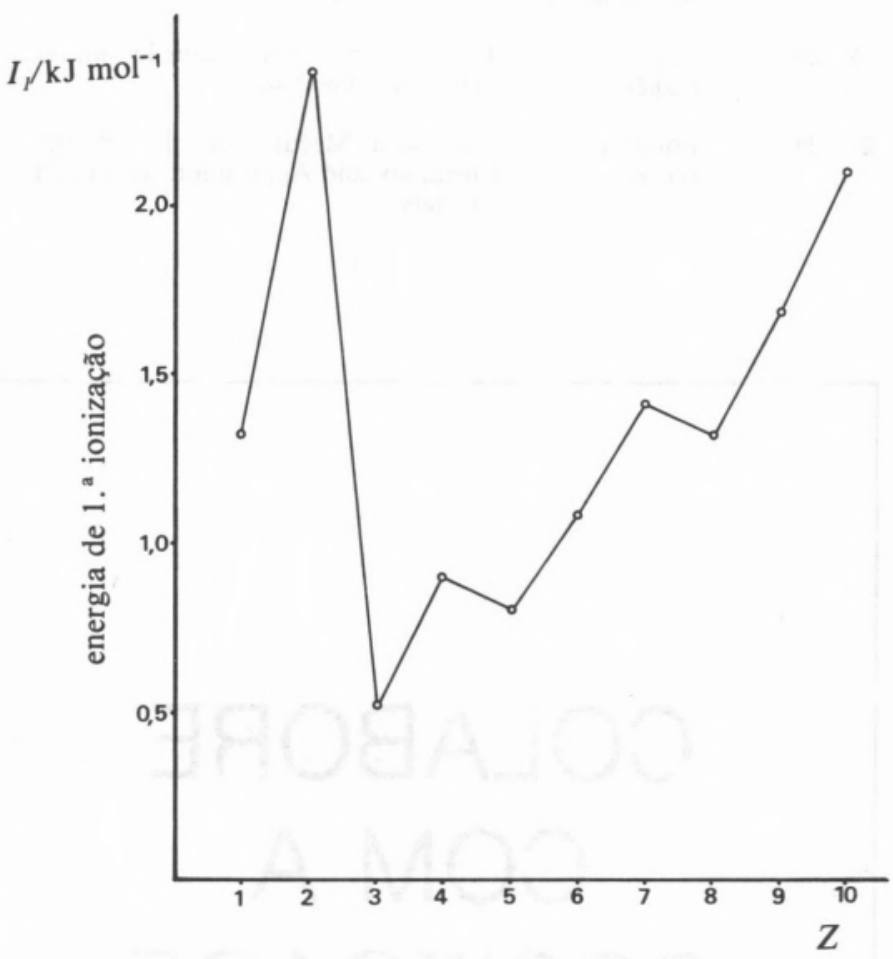

Bibliografia

ASE, Chemical nomenclature, symbols and terminalogy, ASE, Hatfield, 1979.

ASE, SI units, symbols and abbreviations, ASE, Hatfield, 1974. 